\title{
Local and Systemic Pathogenesis and Consequences of Regimen-Induced Inflammatory Responses in Patients with Head and Neck Cancer Receiving Chemoradiation
}

\author{
Elvio G. Russi, ${ }^{1}$ Judith E. Raber-Durlacher, ${ }^{2}$ and Stephen T. Sonis ${ }^{3}$ \\ ${ }^{1}$ Department of Radiation Oncology, University Teaching Hospital A.O. "S. Croce e Carle”, Via M. Coppino 26, 12100 Cuneo, Italy \\ ${ }^{2}$ Department of Oral and Maxillofacial Surgery, Academic Medical Center, University of Amsterdam, Gustav Mahlerlaan 3004, \\ 1081 LA Amsterdam, The Netherlands \\ ${ }^{3}$ Division of Oral Medicine, Brigham and Women's Hospital and the Dana-Farber Cancer Institute and Biomodels, \\ LLC, 75 Francis Street, Boston, MA 02115, USA
}

Correspondence should be addressed to Elvio G. Russi; elviorussi@gmail.com

Received 8 December 2013; Accepted 27 January 2014; Published 16 March 2014

Academic Editor: Inger von Bultzingslowen

Copyright (C) 2014 Elvio G. Russi et al. This is an open access article distributed under the Creative Commons Attribution License, which permits unrestricted use, distribution, and reproduction in any medium, provided the original work is properly cited.

Treatment-related toxicities are common among patients with head and neck cancer, leading to poor clinical outcomes, reduced quality of life, and increased use of healthcare resources. Over the last decade, much has been learned about the pathogenesis of cancer regimen-related toxicities. Historically, toxicities were separated into those associated with tissue injury and those with behavioural or systemic changes. However, it is now clear that tissue-specific damage such as mucositis, dermatitis, or fibrosis is no longer the sole consequence of direct clonogenic cell death, and a relationship between toxicities that results in their presentation as symptom clusters has been documented and attributed to a common underlying pathobiology. In addition, the finding that patients commonly develop toxicities representing tissue injury outside radiation fields and side effects such as fatigue or cognitive dysfunction suggests the generation of systemic as well as local mediators. As a consequence, it might be appropriate to consider toxicity syndromes, rather than the traditional approach, in which each side effect was considered as an autonomous entity. In this paper, we propose a biologically based explanation which forms the basis for the diverse constellation of toxicities seen in response to current regimens used to treat cancers of the head and neck.

\section{Introduction}

The past decade has seen major shifts in how we view the biology and consequences of regimen-related toxicities associated with cancer therapy. Tissue-specific damage such as mucositis, dermatitis, or fibrosis is no longer thought to be the sole consequence of direct clonogenic cell death. A relationship between toxicities that results in their presentation as symptom clusters has been documented and attributed to common underlying pathobiology $[1,2]$. Active roles for the local microbiota and tumour as biologically active contributors and modifiers of toxicity development are being assessed. Genomic differences among patients have been identified which are major determinants of toxicity risk [3-5]. And the finding that patients commonly develop toxicities representing tissue injury (i.e., diarrhoea) outside radiation fields and side effects such as fatigue or cognitive dysfunction suggests the generation of systemic and local mediators. Cumulatively, this information has formed the basis for a robust pipeline of investigative agents that offer the hope of effective toxicity interventions.

Among cancer patients, those being treated for cancers of the head and neck (HNCPs) represent one of the most robust populations to evaluate and analyse focal tissue injury such as mucositis or dermatitis or systemic side effects such as fatigue, cachexia, or cognitive dysfunctions [69]. Furthermore, rarely do patients have a single toxicity. Rather, treatment-related complications appear to occur as nonrandom clusters $[1,2]$, which share a common underlying pathobiological basis. In fact, it might be most appropriate 
to consider the study of "toxicity syndromes," rather than the traditional approach in which each side effect was considered as an autonomous entity.

The historical reductionist view that attributed iatrogenic damage solely to the clonogenic cell death of tissue stem cells, mostly in the epithelium of the entire gastrointestinal tract, has been experimentally reevaluated to reveal that iatrogenic toxicities including mucositis [10, 11], dermatitis [12], and pneumonitis $[13,14]$ represent the culmination of a series of biologically complex events that occur in all directly and indirectly injured tissues [15]. In addition, the observation of toxicities, which are systemically manifested, have provided a rationale for the application of the abscopal effect to normal tissues in addition to tumours [16]. This hypothesis suggests that focal radiation, even in the absence of concomitant chemotherapy (CT), can result in biologically active mediators that have diffuse targets at remote sites. The clustering of CT- and radiotherapy (RT)-induced toxicities sharing common pathobiology reported by Aprile et al. [1] provided a biological basis for clinical observations. Understanding the nature of the genesis of these toxicities is critical to establishing an effective interventional strategy. Based on the pathobiology of diseases which result in similar phenotypes (i.e., chronic fatigue syndrome, Crohn's disease, and Sjogren's syndrome as examples), it seems that inflammatory pathways and mediators are likely candidates for this role.

It is becoming increasingly clear that the wide variety of proteins elicited by CT or RT to cause local toxicities may have significant abscopal effects that put the patient at risk for a systemic inflammatory reaction that, in many ways, resembles what is seen clinically in sepsis. While the true definition of sepsis is not satisfied in cases with no identifiable microbial invasion, the scope of a systemic inflammatory response can result in marked clinical morbidity or even death [17-21]. Moreover, bacteraemia, due to the loss of integrity of a physical barrier (mucosa, skin), are not always associated with sepsis [22, 23] but may lead to sepsis when they are associated with a panoply of nonspecific inflammatory responses [24].

In addition, it has been postulated that an inflammatory response induced by the tumour itself [25] may play a role and, together with inflammation induced by iatrogenic cytolysis, may contribute to the main adverse events in CTRT-treated HNCPs.

In this manuscript, we attempt to develop a biologically based explanation which forms the basis for the diverse constellation of toxicities seen in response to current regimens used to treat cancers of the head and neck.

\section{Mucosal Injury}

Until the late 1990's [26], the historical paradigm of cancer regimen-related epithelial injury held that damage was essentially the consequence of nonspecific clonogenic cell death in which rapidly dividing epithelial basal cells were indiscriminately destroyed by chemotherapy or radiation. This hypothesis was subsequently overturned in favour of a concept which identified that radiation and chemotherapy induce a plethora of biological events, largely in the submucosa, which activate a collection pathways which in turn mediate basal cell injury and death [27, 28]. A role for the local mucosal environment, including microorganisms, has also been suggested [29] but is still in need of study as interventional strategies aimed at eliminating or modifying the microbial flora have failed [30-33]. Furthermore, it is possible that rather than being inert to the effects of radiation, the functional characteristics of the gastrointestinal tract microflora might be inadvertent targets of radiation and, when radiated, undergo changes that modify their potential effects on tissue [34-36].

The evolution of CT-RT-induced mucosal injury was schematically classified in a five-phase model by Sonis [28]: initiation, upregulation/activation, signal amplification, ulceration, and healing. Interestingly, the activation of at least 14 canonical pathways has been identified as a consequence of chemoradiation (CRT). Thus, the "engine" which drives tissue and systemic symptom development is diverse.

2.1. Oxidative Stress and the Innate Immune Response as Initiators. The initiation of RT or CT-induced tissue injury is associated with biological events, clonogenic cell death as a consequence of DNA damage and strand breaks [37], oxidative stress, and activation of the innate immune response. Oxidative stress results in the creation of reactive oxygen species (ROS) inside injured cells $[15,29]$ at a rate that overcomes cell repairing capability [3-5].

ROS created by the ionization of intracellular water [38] cause a spectrum of lesions in cellular macromolecules (e.g., lipid peroxidation) [39]. These macromolecular lesions can damage intracellular organelles such as mitochondria [40, 41], which in turn release additional ROS. ROS further damage cell membranes and connective tissue, stimulate macrophages, and trigger a cascade of critical biological molecules that activate the immune inflammatory response [39, 42-47]. Nuclear factor erythroid 2-related factor-2 (Nrf2) has been implicated as an important element in mediating oxidative stress and preclinical data suggest that it may be a relevant target for toxicity intervention $[48,49]$.

Data supporting a role for the innate immune response in the genesis of radiation injury continues to accumulate. It also seems highly probable that normal cells, made apoptotic or necrotic by CT or RT [50], release endogenous damageassociated molecular patterns (DAMPs) [51] or chemoradiation associated molecular patterns (CRAMPs) [15], which play an integral role in initiating inflammation toxicity. An example of CRAMPs is the high-mobility group box 1 (HMGB1) [52]. In healthy cells, HMGB1 is located in the nucleus, where it facilitates DNA assembly. This molecule is released by necrotic cell death and pulsatile-released by cells made apoptotic by RT and CT [50]. Once outside the cell, HMGB1 has the potential to activate the host's immune system $[15,53]$ via the activation of the multiple surface receptors including Toll like Receptor (TLR)2, TLR4, and Receptor for Advanced Glycation End products (RAGE) [54].

The true biological and clinical consequences of HMGB1 $[55,56]$ are unresolved. The observation that high HMGB1 
serum levels were associated with increased risk of sepsismediated death might be associated with the effectiveness of the molecule as a potent mediator of a systemic inflammatory response. Somewhat perplexing is the observation that HMGB1 activation is more strongly associated with low radiation exposure [57]. In experimental settings, HMGB1 was found to be involved in the loss of endothelial barrier function [58], the increase of both ileal mucosal and alveolar permeability [59-61], and the fostering of bacterial translocation to mesenteric lymph nodes $[58,60]$.

Table 1 summarises the factors hypothesized to be involved in the initiation of the pathobiology of mucositis and other RT-CT associated toxicities sharing the involvement of inflammation mediators. These factors can cause injury to cells, but not of sufficient magnitude from a toxicity standpoint to explain the extensive injury that characterizes the clinical presentation of mucositis [37].

Activation of the biological cascade within minutes [10] of RT and, long before any tissue changes are noted, changes in gene expression are manifest by a diverse group of cells within the targeted tissue including macrophages, endothelial cells, and fibroblasts. A range of genes with diverse functional ramifications is expressed. Whether this is a consequence of damage to cells or, rather, a consequence of the immune system itself needs to be confirmed [15, 99]. However, the involvement of pattern recognition receptors (PRRs) [100] such as TLR [101] and RAGE receptors [102] of the host's innate immune system has been hypothesized. Criswell et al. [103] demonstrated the activation of transcription factors such as NF- $\kappa \mathrm{B}, \mathrm{p} 53$, and SP1 related retinoblastoma, ceramide pathway, and Nrf2 transcription factors $[48,49]$ and their role in the development of radiation-induced mucosal injury has been confirmed by others. At least, 14 canonical pathways associated with the development of CT-RT mucositis are triggered [11]. NF- $\kappa \mathrm{B}$ seems to have a central-hub role in activating inflammation $[28,53,86,104]$; its activation precedes peaks in proinflammatory cytokines in mucosa after CT and upregulates cyclooxygenase-2 (COX-2) $[105,106]$ in submucosal fibroblasts and endothelial cells after radiation.

Disruption of connective tissue fibronectin leads to the deregulation of matrix metalloproteinases (MMP) [81, 107] which impact tissue injury and inflammation. In animal model studies, a significant alteration in both gene expression-tissue levels of MMPs and tissue inhibitor of metalloproteinase (TIMPs) following CT was found to be correlated with histopathological alterations [108].

Finally, the activation of the peripheral nervous system via pain fibres is conceivable. The presence of receptors (e.g., TLR4 and CD14) for inflammatory products on nociceptive fibres has been shown $[73,109]$. The activation of peripheral nerve endings via these receptors [74] ultimately results in the local release of several neurotransmitters and neuropeptides (substance P and calcitonin gene-related peptide 1(CGRP1)), which have strong vasodilatory and chemotactic properties [110]. This may explain the reversible pruritus and faint erythema that develop during the first hours after irradiation $[75,76,111]$.

\subsection{Signal Amplification and Feedback}

2.2.1. Local Effects: Intracellular and Intercellular Signalling Loops. Many of the proteins produced during the primary damage response (upregulation phase) also amplify proinflammatory pathways which intensifies primary damage [28]. Accordingly, a broad range of biologically active proteins accumulates and targets the mucosal tissues (endothelial, epithelial, mesenchymal, and neuronal endings) triggering intracellular and intercellular feedback mechanisms. These feedback mechanisms may induce "vicious circles," which can also involve distant organs via neuronal and bloodstream networks [86].

Below, we present examples of interrelated feedback mechanisms that may act alone or in concert and are thought to play a role in the pathobiology of tissue-centric toxicities such as mucositis and dermatitis.

Activation of Transcription Factors (NF- $\kappa B$ )-Cytokines (e.g., TNF- $\alpha$ ) Transcription Factors (NF- $\kappa B$ ) Loop. NF- $\kappa$ B, upregulated in the previous phase, acts as a "gatekeeper" for various inflammatory pathways one of which is the proinflammatory pathway characterized by cytokines [10] such as TNF, IL$6[112,113]$, and IL-1 $\beta[12,87]$. In turn, these cytokines (particularly TNF- $\alpha$ ) are potent activators of NF- $\kappa \mathrm{B}[10]$, sphingomyelinase [114-116], and members of the TNF receptor family [46]. These loops drive the NF- $\kappa \mathrm{B}$ and ceramide pathways to produce and accelerate tissue injury and initiate mitogen-activated protein kinase (MAPK) signalling. MAPK signalling then activates c-JUN aminoterminal kinase [117], which plays a role in regulating the AP1 transcription factor, which, in turn, is thought to affect MMP secretion $[82,107$, 108].

In addition, NF- $\kappa \mathrm{B}$ upregulates cyclooxygenase-2 (COX$2)$, an inducible enzyme involved in inflammation, through its role in prostaglandin production $[106,118]$. COX-2 expression parallels with the development of ulcerative mucositis.

Coupled with proinflammatory cytokines, it is now apparent that anti-inflammatory cytokines such as IL-10 [119], IL-11 [120, 121] and the anti-inflammatory amino acid decapeptide (RDP58) [122] play a key inflammatory role in both oral and GI RT/CT toxicities [112, 121, 123-126].

The activation of this "cytokine storm" favours the chemoattraction of immune cells (mononuclear cells and macrophages) causing local infiltration and oedema.

The importance of inflammatory pathways in regimenrelated mucosal injury has potential therapeutic leverage. Interventions aimed at attenuating proinflammatory cytokines or stimulating anti-inflammatory cytokines may offer a way to prevent toxicities [120, 121, 127-131].

Peripheral Neuronal Amplification Loop. While a role of neurotransmitters and neuropeptides in mucosal injury has not been well studied, it is quite possible that the activation of peripheral nerve endings and the release of several neurotransmitters and neuropeptides (substance $\mathrm{P}$ and calcitonin gene-related peptide $\alpha$ (CGRP1)) lead to the recruitment of innate immune cells. Studies of genetic predilection for regimen-related toxicities demonstrate the presence of single 
TABLE 1: Local and systemic pathogenesis and consequences of regimen-induced inflammatory responses.

Mucosal injury Relevant clinical consequences

Cellular damage induced by CT-RT

(1) Initiation: oxidative stress and the innate immune response

(i) X-rays or mucotoxic drugs cause direct DNA break [28, 37].

(ii) Generation of ROS [38].

(iii) ROS damage lipids, DNA, connective tissue, and other biomolecules [39-41].

(iv) Cells die in epithelia, endothelia [62, 63], and submucosal tissue [28].

Release of inflammatory substances

The components passively released from injured cells become a danger signal that alert the host

of the dying cells and play an integral role in initiating toxicity [15]:

(i) intracellular proinflammatory CRAMP (e.g., HMBG1 [64, 65], mitochondrial derived

Silent phase substances [40] ect.),

(ii) intracellular enzymes (lysosomial), which activate extracellular proinflammatory DAMPs $[66,67]$ (which in turn activate other cascades, i.e., clotting, fibrinolytic, and kin cascades),

(iii) altered redox state of the injured tissue [44],

(iv) presynthesised interleukins (IL-1 $\alpha$, IL-33) [68-70],

(v) released intracellular hidden antigens which activate Complement via antibodies (Complement can be regarded both as a PRR system and an effector system [71, 72]).

(2) Upregulation/activation

(i) Activation of PRR, IL-1R, and RAGE receptors of the host's innate immune system $[15,53]$ and of the peripheral nociceptive nervous fibres [73, 74].

(ii) The main canonical pathways associated with the development of CT-RT mucositis [11] as follows:

(1) nitrogen metabolism

(2) TLR signalling

(3) NF- $\kappa$ B signalling

(4) B cell receptor signalling

(5) PI3K/AKT signalling

(6) G2/M DNA damage checkpoint

(7) SAPK/JNK signalling

(8) P38 MAPK signalling

(9) Wnt/B-catenin signalling

(10) glutamate receptor signalling

(11) integrin signalling

(12) VEGF signalling

(13) IL-6 signalling

(14) death receptor signalling

Inflammation: transient faint erythema and pruritus that can develop during the first hours after irradiation $[75,76]$.

Local effects: intracellular and intercellular signalling loops

(i) Activation of Transcription factors (NF- $\kappa \mathrm{B})$-Cytokines (e.g., TNF- $\alpha$ )-Transcription factors (NF- $\kappa \mathrm{B})$ loop [28]

(ii) Peripheral neuronal amplification loop $[77,78]$

(iii) Inflammation-coagulation loop [79, 80]

(iv) ROS-extracellular matrix (ECM) - immune cell loop [81, 82]

(v) Endothelial-epithelial loop [83-85]

Abscopal effects and toxicities: systemic and interorgan signalling [71]) (Figure 1)

(i) Elevated serum levels of NF- $\kappa$ B, TNF- $\alpha$, IL-1 and IL-6 $[86,87]$

(ii) Genetic changes in peripheral blood monocytes [11].

(iii) Plasma cascades (Complement, coagulation, fibrinolytic, and kallikrein-kinin systems) [71]

(iv) Acute phase proteins (Pentraxins-C-RP/SAP, Factor XII, Complement proteins ect.) [71]

(v) HPA axis activated by circulating cytokines (IL-6) and by peripheral nervous system $[88,89]$

Local inflammation:

Oedema,

Cellular (mononuclear cells/macrophage and neutrophil) infiltration Epithelial thinning: hypersensitiveness Vasodilatation: erythema 
TABle 1: Continued.

Mucosal injury Relevant clinical consequences

(4) Ulcerative/microbiological phase

(i) Mucosal barrier injury

(ii) Bacterial colonisation: increases follow, not precede, ulceration/MBI $[95,96]$

(iii) Microflora shifts due to CT, xerostomia, antibiotic use, and neutropenia.

(iv) Microorganisms penetrate the disrupted mucosa and stimulate infiltrating macrophages to produce additional proinflammatory cytokines.

${ }^{*}$ Cachexia: weight loss $>5 \%$ or BMI $<20$ plus decreased muscle strength, fatigue, anorexia, low lean mass index, and abnormal biochemistry (increased C-RP and IL-6 inflammatory markers, anaemia, and low serum albumin) [97, 98].

Abbreviations see the text.

nucleotide polymorphisms associated with genes for both substance P and CGRP1 [132]. These mechanisms could potentiate the local immune response and thereby lead to the activation of additional nociceptive sensory nerves in a positive feedback manner [77].

Inflammation-Coagulation Loop. Endothelial damage and iatrogenic-induced cytokine synthesis upregulate procoagulation $[79,80,133]$. Indeed, laboratory and in vivo studies showed the potential of upregulating coagulation "tissue factor" (TF) by means of inflammatory mediators such as TNF- $\alpha$ [134], C-reactive protein (C-RP) [135], and long pentraxin3 [136] (PTX3). In turn, TF generates coagulant mediators (FVIIa, FXa, FIIa, and Fibrin) that upregulate inflammatory mediators by means of protease-activated receptors (PARs) and TLR-4 [137-139].

This triggers an inflammation-coagulation circuit that increases local and/or systemic proinflammatory and procoagulative activity $[137,139]$. The potential therapeutic implications of this loop is illustrated by the finding that hirudin, a direct thrombin inhibitor, was observed to ameliorate radiation induced intestinal toxicity in a rat model [140].

ROS-Extracellular Matrix (ECM)-IMMUNE Cell Loop. The extracellular matrix (ECM) is a complex structural network of fibrous proteins, proteoglycans, and glycoproteins. Aside from its role during the healing phase of mucositis, during which ECM signalling plays a critical role in establishing the fate of wound resolution, it also may have an active role during the more proximal aspects of radiation or chemotherapyinduced damage. A relationship between changes in ECM component expression and chemotherapy-induced intestinal injury was recently reported [141]. Furthermore, ECM mediates mesenchymal-epithelial communication and is also a reservoir of latent cytokines (such as TGF- $\beta$ and IL1$\beta$ ), which can be activated in consequence of the action of proteases (plasmin and thrombin) and ROS [142, 143]. Activation of MMPs through oxidants, which are generated by leukocytes or other cells, follows [144]. In turn, MMPs control chemokine activity [82]. Activated cytokines and chemokines, in turn, attract and activate other immune cells (such as neutrophils), which in turn, release ROS, thus restarting the loop.

Endothelial-Epithelial Loop. Morphologic evidence from histological studies using light and electron microscopy shows damage to the microvascular endothelial cells occurring earlier than that to the epithelium $[83,121]$. Vascular injury involves microvessels and includes endothelial damage and coagulative occlusion [79]. Endothelial-cell apoptosis [84] interrupts the protective effect on the epithelia due to the endothelial-produced keratinocyte growth factor (KGF) [85], which activates the protective Nrf2-antioxidant pathway [48] in the epithelia. This results in epithelial thinning due to a loss of epithelial stem cells, which in turn generates further endothelial damage, ultimately leading to ulceration.

2.2.2. Abscopal Effects and Toxicities: Systemic and Interorgan Signalling. The abscopal effect was the term that Mole proposed sixty years ago to describe the observation that patients demonstrate a range of responses distant from the radiated tumour [145]. Initially, abscopal effects were focused on distant tumour response, but it is now clear that the same phenomenon is relevant to normal tissue response and the aetiology of systemic side effects of treatment. In an excellent review of the topic, Siva et al. note that "localized irradiation perturbs the organism as a whole" [16]. They propose that the basis of the response stems from the development of a "chronic inflammatory environment and overall genomic instability." The finding that focal radiation produces changes in gene expression detectable in peripheral blood monocytes consistent with pathways known to play a role in radiation toxicity [11] supports this hypothesis. The consequences of an abscopal effect may explain clinical observations of both "systemic" (fatigue, cognitive dysfunction, cachexia, etc.) and tissue centric (diarrhoea, nausea and vomiting, etc.) toxicities (Figure 1).

The two major mediators of the abscopal effect are cytokines and the immune system [16]. In healthy humans, cytokines are usually produced at low constitutive levels (picograms $/ \mathrm{mL}$ ) in plasma, and they function in an endo-, para-, or autocrine manner [146]. In inflamed (injured and/or infected) tissues, there is an excessive cytokine production that can become detectable in peripheral blood [11, 86, 147]. As noted above, a cytokine cascade is an established consequence of RT. The production of proinflammatory cytokines, particularly IL-1 $\beta$, IL- 6 , and TNF- $\alpha$, occurs not only in tissue, but in peripheral blood and increased levels of systemic proinflammatory cytokines which correlate with nonhaematological toxicities [121, 148-151] after RT, suggesting that the mediators of toxicities are not simply compartmentalised 


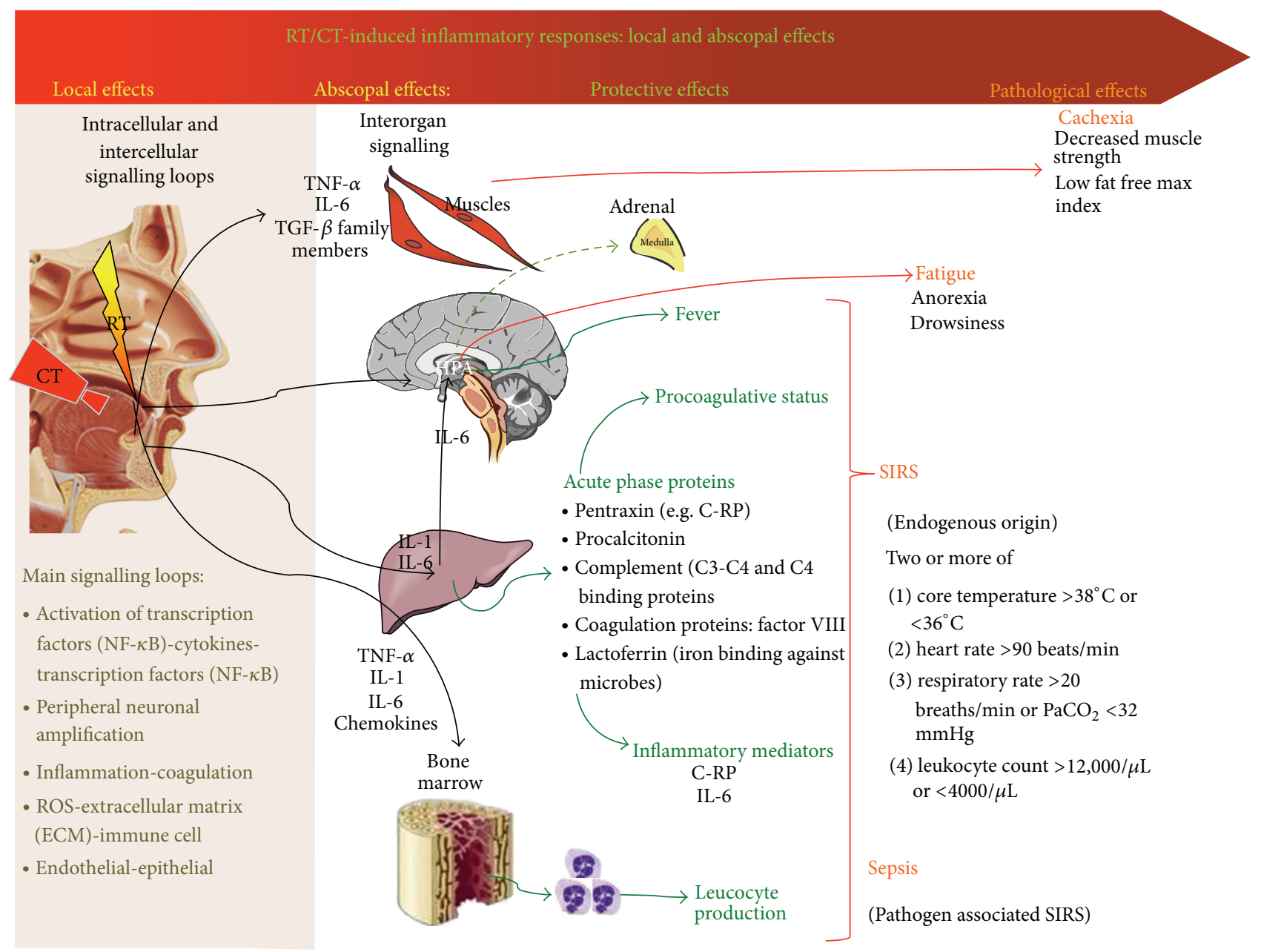

FIGURE 1: RT/CT-induced inflammatory responses: local and abscopal effects. Intracellular and intercellular signalling loops follow initiation and upregulation due to the local effects of chemoradiation on the exposed tissues. Released cytokines act not only locally but also on other organs and tissues (Interorgan signalling). On muscles they can alter energetic metabolism (thus favouring cachexia). On HPA (hypothalamicpituitary-adrenal axis) they cause fever and fatigue symptoms. In the liver they provoke the synthesis of acute phase proteins that in turn act in a procoagulative and general inflammatory and antiinflammatory sense. All these effects can lead to systemic inflammatory response syndrome (SIRS) or sepsis. Abbreviations: $\mathrm{PaCO}_{2}$ : arterial carbon dioxide tension. For other abbreviations, see the text.

into the radiation field. Indeed, peripheral activated cells (such as B-lymphocytes [152], myeloid lineage cells [149], and monocytes [11]) have an increased transcription of inflammation-related genes, particularly those responsive to the proinflammatory NF- $\kappa$ B transcription control pathway. In addition, it is conceivable that the use of concomitant CT offered an additional opportunity for the systemic effects to occur $[11,62,153]$.

Cytokine production from activated cells is likely enhanced by activation of an innate immune response (see above) triggered by RT or CRT and tissue-borne pathogens. As a result peripheral blood levels of cytokines increase and remain elevated as has been reported in patients being treated for cancers of the head and neck [154]. A similar inflammatory response has been noted subsequent to CTinduced injury to the oral or gastrointestinal mucosal barrier where a systemic inflammatory response is elicited when various PRRs expressed by nonepithelial cells within the mucosa (e.g., macrophages, neutrophils, and dendritic cells) are exposed to severe endogenous (DAMP) and exogenous (PAMP) stress [32, 155-158]. For example, Blijlevens and colleagues reported that mucositis induced a systemic inflammatory response characterized by fever in neutropenic stem cell recipients, even in the absence of bacteraemia [156].

The impact of systemic cytokines as mediators of clusters of toxicities was suggested by Aprile et al., who used a Bayesian analytical approach in a cohort of patients receiving CT to treat colorectal cancer. They noted that some toxicities were more frequently interconnected than would be expected by chance [1]. The most frequently associated toxicities were those that probably share a common pathobiology (fever, fatigue, anorexia, and weight loss) [1]. Furthermore, some authors $[2,159]$ showed the plausibility of these associations, whereas others showed that it is possible to predict both the 
risk of oral mucositis [160] and severe sepsis [161, 162] by the dosage of plasma levels of inflammatory mediators in patients receiving mucotoxic treatments.

Thus, it is conceivable that the CT-RT-induced inflammation can act both locally, as a consequence of a paracrine signalling amplification, and systemically, as a consequence of a sort of endocrinal-like signalling amplification.

Behavioural Examples of Abscopal Toxicities. While behavioural toxicities such as fatigue and cognitive dysfunction are commonly recognised to occur among patients receiving CRT, it is only recently that the physiological basis for these changes has been assessed in the context of focal $\mathrm{RT}$ regimens. We know that the nervous system can be activated systemically by circulating cytokines, such as IL-6 [88]. The finding that the microvasculature in the mediobasal hypothalamus has a specialised fenestrated endothelium might explain the transfer of cytokines from the circulation to the central nervous system (CNS), where they in turn could stimulate the local production of cytokines [89] or initiate behavioural changes. Thus, while the sensory nervous system activates the sympathetic nervous system both segmentally, at the level of the spinal cord, and centrally, the circulating cytokines (such as IL-6) provide a sensor for the extent of inflammation and the consequent energy needed at a systemic level $[161,162]$. Specifically, the hypothalamicpituitary-adrenal (HPA) axis has been identified as a possible conduit for the mediation of behavioural toxicities. Concomitantly, parasympathetic activity, which has anti-inflammatory effects $[163,164]$, is inhibited during initial inflammation [165, $166]$ in order to modulate adequate inflammation intensity. At any rate, parasympathetic activity plays a role in systemic inflammation such as sepsis. Indeed the experimental stimulation of the peripheral vagus nerve strongly inhibits lipopolysaccharide-induced acute inflammation [167] and leukocyte recruitment [168].

To further support the link between CT-RT induced inflammation and the clinical symptoms frequently associated to mucositis, recent literature has shown that fatigue [90, 169], cachexia [94], and Systemic Inflammatory Response Syndrome (SIRS) $[71,169,170]$ have been associated to a deregulated systemic inflammatory response to CT-RT of the organism (Figure 1).

(a) Fatigue and Systemic Inflammation. Fatigue is defined as the physical and/or mental weariness resulting from exertion: an inability to continue exercise at the same intensity with a resultant deterioration in performance $[97,171]$.

The underlying mechanism of cancer-related fatigue (CRF) remains unclear; it is probably due to multifactorial causes [172]. Prue's systematic review [173] found that there were significant increases in fatigue during anticancer therapy (fatigue prevalence 39\%-90\%).

Fatigue has been demonstrated to increase during RT $[174,175]$ and does not depend on concomitant increases in emotional distress $[176,177]$. Yet two randomised controlled trials have reported that while paroxetine improves the mood of patients undergoing outpatient CT, it has no effect on fatigue relief $[178,179]$. Taken together, these studies suggest that fatigue and depression/psychological distress are related but distinct phenomena. A number of authors have suggested that CRF may be related to an elevated or prolonged inflammatory response in cancer patients [180]. Two recent reviews showed a positive association between $\mathrm{CRF}$ and inflammatory/immunity circulating marker levels during RT and CT $[90,181]$. However, the majority of studies was cross-sectional in nature and did not use well-validated fatigue assessment instruments.

(b) Cachexia and Systemic Inflammation. A new definition/classification [97, 98] of cancer cachexia has only recently been made (Table 1). Since no standard definition had been available, cachexia was previously underdiagnosed [182]. Even today, physicians usually treat the symptoms of anorexia, weight loss, and insulin resistance without diagnosing cachexia. In the retrospective study by Fox et al. [182], physicians diagnosed cachexia only in $6.1 \%$ of 246 patients, even though $19.9 \%$ of them had lost $>5 \%$ of their body weight and $37 \%$ of them had at least one of the cachexia definitions.

Cancer cachexia has a multifactor pathogenesis due to tumour-releasing factors [183, 184] or to treatment [185]/ sepsis immune responses, or both.

Indeed, the circulating inflammatory cytokines such as TNF- $\alpha[186,187]$, IL-6, TGF $\beta$ family members (e.g., myostatin and activin) seem to have a role in inducing cachexia acting both peripherally on the muscle and centrally on the CNS.

Peripherally, cytokines activate NF- $\kappa \mathrm{B}$ in muscles [188] and promote muscle degeneration by accelerating protein breakdown [91] and by dysregulating protein-turnover leading to catabolism [189].

Centrally, the cytokines act especially on HPA axis. Indeed, the rise in circulating cytokines has been implicated in the physiologic and behavioural responses to inflammation in rodents, including anorexia [190], HPA axis activation [191], and fever [192].

In humans, IL-6 [193] seems to have an important role. Recent trials on a monoclonal anti-IL- 6 antibody used in order to contrast lung cancer patients' weight loss have shown that it is able to reverse anorexia, fatigue, and anaemia, but it had no significant effect on the lean body mass loss [194].

The study by Silver et al. [185], who treated seventeen HNCPs with induction CT followed by concomitant CT-RT, is interesting because it related wasting syndrome to CT-RT. These patients showed a wasting syndrome with a statistically lean body mass loss $(P=.005)$, declined total physical activity, increased resting energy expenditure $(P=.019)$, and increased inflammatory cytokines and inflammatory mediators (C-reactive protein (C-RP), $P=.09$ and IL-6, $P=.08)$ ) during concomitant CT-RT even though there were no significant differences in energy intake or calorie/nitrogen ratio from pretreatment to posttreatment.

Other authors have found that C-RP was an independent predictor of weight loss $(P<.001)$ in HNCPs treated with CRT [195]. 
We hypothesise that in HNCPs, the cachexia syndrome is particularly reinforced by systemic inflammation induced by oral mucositis and reduced energy intake due to reduced swallowing capacity $[195,196]$.

\section{Conclusions}

Much has been learned about the pathogenesis of cancer regimen-related toxicities. The complexity of the molecular and cellular response to chemotherapy and radiation, the observation of distant or systemic toxicities following focal radiation therapy, and the discovery of genomic features that are associated with toxicity risk have only found their way to mainstream thinking in the past decade.

It is now clear that the molecular events that occur within tissues following radiation begin within seconds of the challenge. And the consequences of the resulting biological cascade not only result in local tissue injury, but in the release of active proteins in the circulation. It is this systemic cytokine storm and its companion molecules that lead to abscopal effects in normal tissue. Clinically, these are manifest by both distant distal injury and by behavioural toxicities such as fatigue, cognitive dysfunction, and cachexia.

Furthermore, it is now clear that the clustering of toxicity symptoms that is most commonly not random. Rather, these changes, which distinct clinically represent the consequences of shared biology. It is the target tissue responding to common drivers that results in the distinct phenotypes. Thus, the concept of toxicity syndromes defined, not clinically, but by common bioetiological features is becoming increasingly important in the determination of patient status and in establishing pharmacological targets.

Ultimately, it is the discovery and definition of the pathways that lead to toxicities that will define and optimise a comprehensive approach to their amelioration.

\section{Conflict of Interests}

The authors declare that there is no conflict of interests regarding the publication of this paper.

\section{Acknowledgment}

The authors would like to thank "Lega Italiana per la Lotta contro i Tumori Sez. di Cuneo" for its grant.

\section{References}

[1] G. Aprile, M. Ramoni, D. Keefe, and S. Sonis, "Application of distance matrices to define associations between acute toxicities in colorectal cancer patients receiving chemotherapy," Cancer, vol. 112, no. 2, pp. 284-292, 2008.

[2] C. Xiao, A. Hanlon, Q. Zhang et al., "Symptom clusters in patients with head and neck cancer receiving concurrent chemoradiotherapy," Oral Oncology, vol. 49, pp. 360-366, 2013.

[3] C. Andreassen, "The biological basis for differences in normal tissue response to radiation therapy and strategies to establish predictive assays for individual complication risk," in Pathobiology of Cancer Regimen-Related Toxicities, S. T. Sonis and D. M. Keefe, Eds., pp. 19-33, Springer, New York, NY, USA, 2013.
[4] N. Pratesi, M. Mangoni, I. Mancini et al., "Association between single nucleotide polymorphisms in the XRCC1 and RAD51 genes and clinical radiosensitivity in head and neck cancer," Radiotherapy and Oncology, vol. 99, no. 3, pp. 356-361, 2011.

[5] J. Werbrouck, K. de Ruyck, F. Duprez et al., "Acute normal tissue reactions in head-and-neck cancer patients treated with IMRT: influence of dose and association with genetic polymorphisms in DNA DSB repair genes," International Journal of Radiation Oncology, Biology, Physics, vol. 73, no. 4, pp. 1187-1195, 2009.

[6] G. Numico, E. G. Russi, R. Vitiello et al., "Gemcitabine and cisplatin in a concomitant alternating chemoradiotherapy program for locally advanced head-and-neck cancer: a pharmacology-guided schedule," International Journal of Radiation Oncology, Biology, Physics, vol. 66, no. 3, pp. 731-737, 2006.

[7] M. Merlano, E. Russi, M. Benasso et al., "Cisplatin-based chemoradiation plus cetuximab in locally advanced head and neck cancer: a phase II clinical study," Annals of Oncology, vol. 22, no. 3, pp. 712-717, 2011.

[8] A. A. Forastiere, H. Goepfert, M. Maor et al., "Concurrent chemotherapy and radiotherapy for organ preservation in advanced laryngeal cancer," The New England Journal of Medicine, vol. 349, no. 22, pp. 2091-2098, 2003.

[9] A. Trotti, L. A. Bellm, J. B. Epstein et al., "Mucositis incidence, severity and associated outcomes in patients with head and neck cancer receiving radiotherapy with or without chemotherapy: a systematic literature review," Radiotherapy and Oncology, vol. 66, no. 3, pp. 253-262, 2003.

[10] S. T. Sonis, "The biologic role for nuclear factor-kappaB in disease and its potential involvement in mucosal injury associated with anti-neoplastic therapy," Critical Reviews in Oral Biology and Medicine, vol. 13, no. 5, pp. 380-389, 2002.

[11] S. Sonis, R. Haddad, M. Posner et al., "Gene expression changes in peripheral blood cells provide insight into the biological mechanisms associated with regimen-related toxicities in patients being treated for head and neck cancers," Oral Oncology, vol. 43, no. 3, pp. 289-300, 2007.

[12] M. Janko, F. Ontiveros, T. J. Fitzgerald, A. Deng, M. DeCicco, and K. L. Rock, "IL-1 generated subsequent to radiationinduced tissue injury contributes to the pathogenesis of radiodermatitis," Radiation Research, vol. 178, pp. 166-172, 2012.

[13] Y. Chen, P. Rubin, J. Williams, E. Hernady, T. Smudzin, and P. Okunieff, "Circulating IL-6 as a predictor of radiation pneumonitis," International Journal of Radiation Oncology, Biology, Physics, vol. 49, no. 3, pp. 641-648, 2001.

[14] M. A. T. Hildebrandt, R. Komaki, Z. Liao et al., "Genetic variants in inflammation-related genes are associated with radiationinduced toxicity following treatment for non-small cell lung cancer," PLoS ONE, vol. 5, no. 8, Article ID e12402, 2010.

[15] S. T. Sonis, "New thoughts on the initiation of mucositis," Oral Diseases, vol. 16, no. 7, pp. 597-600, 2010.

[16] S. Siva, M. P. Macmanus, R. F. Martin, and O. A. Martin, "Abscopal effects of radiation therapy: a clinical review for the radiobiologist," Cancer Letters, 2013.

[17] F. B. Cerra, "The systemic septic response: multiple systems organ failure," Critical Care Clinics, vol. 1, no. 3, pp. 591-607, 1985.

[18] R. C. Bone, "The pathogenesis of sepsis," Annals of Internal Medicine, vol. 115, no. 6, pp. 457-469, 1991.

[19] A. Argiris, B. E. Brockstein, D. J. Haraf et al., "Competing causes of death and second primary tumors in patients with locoregionally advanced head and neck cancer treated with 
chemoradiotherapy," Clinical Cancer Research, vol. 10, no. 6, pp. 1956-1962, 2004.

[20] L. K. Mell, J. J. Dignam, J. K. Salama et al., "Predictors of competing mortality in advanced head and neck cancer," Journal of Clinical Oncology, vol. 28, no. 1, pp. 15-20, 2010.

[21] D. C. Angus and T. van der Poll, "Severe sepsis and septic shock," The New England Journal of Medicine, vol. 369, pp. 840-851, 2013.

[22] L. Forner, T. Larsen, M. Kilian, and P. Holmstrup, "Incidence of bacteremia after chewing, tooth brushing and scaling in individuals with periodontal inflammation," Journal of Clinical Periodontology, vol. 33, no. 6, pp. 401-407, 2006.

[23] J. E. Raber-Durlacher, A. M. G. A. Laheij, J. B. Epstein et al., "Periodontal status and bacteremia with oral viridans streptococci and coagulase negative staphylococci in allogeneic hematopoietic stem cell transplantation recipients: a prospective observational study," Support Care Cancer, vol. 21, pp. 1621$1627,2013$.

[24] A. Lever and I. Mackenzie, "Sepsis: definition, epidemiology, and diagnosis," British Medical Journal, vol. 335, no. 7625, pp. 879-883, 2007.

[25] P. Castellani, E. Balza, and A. Rubartelli, "Inflammation, DAMPs, tumor development, and progression: a vicious circle orchestrated by redox signaling," Antioxidants \& Redox Signaling, vol. 20, no. 7, pp. 1086-1097, 2013.

[26] P. B. Lockhart and S. T. Sonis, "Alterations in the oral mucosa caused by chemotherapeutic agents. A histologic study," Journal of Dermatologic Surgery and Oncology, vol. 7, no. 12, pp. 1019$1025,1981$.

[27] J. M. Bowen and D. M. K. Keefe, "New pathways for alimentary mucositis," Journal of Oncology, vol. 2008, Article ID 907892, 7 pages, 2008.

[28] S. T. Sonis, "The pathobiology of mucositis," Nature Reviews Cancer, vol. 4, no. 4, pp. 277-284, 2004.

[29] A. M. G. A. Laheij, J. J. de Soet, P. A. von dem Borne et al., "Oral bacteria and yeasts in relationship to oral ulcerations in hematopoietic stem cell transplant recipients," Supportive Care in Cancer, vol. 20, pp. 3231-3240, 2012.

[30] A. Barasch, S. Elad, A. Altman, K. Damato, and J. Epstein, "Antimicrobials, mucosal coating agents, anesthetics, analgesics, and nutritional supplements for alimentary tract mucositis," Supportive Care in Cancer, vol. 14, no. 6, pp. 528532, 2006.

[31] R. Corvò, M. Amichetti, A. Ascarelli et al., "Effects of fluconazole in the prophylaxis of oropharyngeal candidiasis in patients undergoing radiotherapy for head and neck tumour: results from a double-blind placebo-controlled trial," European Journal of Cancer Care, vol. 17, no. 3, pp. 270-277, 2008.

[32] J. P. Donnelly, L. A. Bellm, J. B. Epstein, S. T. Sonis, and R. P. Symonds, "Antimicrobial therapy to prevent or treat oral mucositis," The Lancet Infectious Diseases, vol. 3, no. 7, pp. 405412, 2003.

[33] S. El-Sayed, A. Nabid, W. Shelley et al., "Prophylaxis of radiation-associated mucositis in conventionally treated patients with head and neck cancer: a double-blind, phase III, randomized, controlled trial evaluating the clinical efficacy of an antimicrobial lozenge using a validated mucositis scoring system," Journal of Clinical Oncology, vol. 20, no. 19, pp. 39563963, 2002.

[34] J. J. Napeñas, M. T. Brennan, S. Coleman et al., "Molecular methodology to assess the impact of cancer chemotherapy on the oral bacterial flora: a pilot study," Oral Surgery, Oral Medicine, Oral Pathology, Oral Radiology and Endodontology, vol. 109, no. 4, pp. 554-560, 2010.

[35] Y. Soga, Y. Maeda, F. Ishimaru et al., "Bacterial substitution of coagulase-negative staphylococci for streptococci on the oral mucosa after hematopoietic cell transplantation," Supportive Care in Cancer, vol. 19, no. 7, pp. 995-1000, 2011.

[36] W. J. F. M. van der Velden, J. P. Donnelly, and N. M. A. Blijlevens, "Lymphocyte subsets, granulocytecolony-stimulating factor responsiveness and post-stem cell transplantation infections: mucositis is the underestimated confounder?" Cytotherapy, vol. 14, no. 3, pp. 381-383, 2012.

[37] J. W. Denham and M. Hauer-Jensen, "The radiotherapeutic injury-a complex "wound"' Radiotherapy and Oncology, vol. 63, no. 2, pp. 129-145, 2002.

[38] M. M. Odyuo and R. N. Sharan, "Differential DNA strand breaking ablities of $\mathrm{OH}$ and ROS generating radiomimetic chemicals and $\gamma$-rays: study of plasmid DNA, pMTa4, in vitro," Free Radical Research, vol. 39, no. 5, pp. 499-505, 2005.

[39] E. Azzam, S. Toledo, A. Harris, V. Ivanov, H. Zhou, S. Amundson et al., "The ionizing radiation-induced bystander effect: evidence, mechanism, and significance," in Pathobiology of Cancer Regimen-Related Toxicities, S. T. Sonis and D. M. Keefe, Eds., pp. 35-61, Springer, New York, NY, USA, 2013.

[40] D. V. Krysko, P. Agostinis, O. Krysko et al., "Emerging role of damage-associated molecular patterns derived from mitochondria in inflammation," Trends in Immunology, vol. 32, no. 4, pp. 157-164, 2011.

[41] J. K. Leach, G. van Tuyle, P.-S. Lin, R. Schmidt-Ullrich, and R. B. Mikkelsen, "Ionizing radiation-induced, mitochondriadependent generation of reactive oxygen/nitrogen," Cancer Research, vol. 61, no. 10, pp. 3894-3901, 2001.

[42] V. E. Arterbery, W. A. Pryor, L. Jiang et al., "Breath ethane generation during clinical total body irradiation as a marker of oxygen-free-radical-mediated lipid peroxidation: a case study," Free Radical Biology and Medicine, vol. 17, no. 6, pp. 569-576, 1994.

[43] T. Hayashi, Y. Kusunoki, M. Hakoda et al., "Radiation dosedependent increases in inflammatory response markers in Abomb survivors," International Journal of Radiation Biology, vol. 79, no. 2, pp. 129-136, 2003.

[44] M. T. Lotze, H. J. Zeh, A. Rubartelli et al., “The grateful dead: damage-associated molecular pattern molecules and reduction/oxidation regulate immunity," Immunological Reviews, vol. 220, no. 1, pp. 60-81, 2007.

[45] K. Neriishi, E. Nakashima, and R. R. Delongchamps, "Persistent subclinical inflammation among A-bomb survivors," International Journal of Radiation Biology, vol. 77, no. 4, pp. 475-482, 2001.

[46] S. T. Sonis, "Pathobiology of oral mucositis: novel insights and opportunities," Journal of Supportive Oncology, vol. 5, no. 9, pp. 3-11, 2007.

[47] T. Ueda, Y. Toyoshima, T. Moritani et al., "Protective effect of dipyridamole against lethality and lipid peroxidation in liver and spleen of the ddY mouse after whole-body irradiation," International Journal of Radiation Biology, vol. 69, no. 2, pp. 199204, 1996.

[48] S. Braun, C. Hanselmann, M. G. Gassmann et al., "Nrf2 transcription factor, a novel target of keratinocyte growth factor action which regulates gene expression and inflammation in the healing skin wound," Molecular and Cellular Biology, vol. 22, no. 15, pp. 5492-5505, 2002. 
[49] J. T. McDonald, K. Kim, A. J. Norris et al., "Ionizing radiation activates the Nrf2 antioxidant response," Cancer Research, vol. 70, no. 21, pp. 8886-8895, 2010.

[50] G. Srikrishna and H. H. Freeze, "Endogenous damageassociated molecular pattern molecules at the crossroads of inflammation and cancer," Neoplasia, vol. 11, no. 7, pp. 615-628, 2009.

[51] S.-Y. Seong and P. Matzinger, "Hydrophobicity: an ancient damage-associated molecular pattern that initiates innate immune responses," Nature Reviews Immunology, vol. 4, no. 6, pp. 469-478, 2004.

[52] M. E. Bianchi, "DAMPs, PAMPs and alarmins: all we need to know about danger," Journal of Leukocyte Biology, vol. 81, no. 1, pp. 1-5, 2007.

[53] S. T. Sonis, “Oral mucositis," Anti-Cancer Drugs, vol. 22, no. 7, pp. 607-612, 2011.

[54] G. P. Sims, D. C. Rowe, S. T. Rietdijk, R. Herbst, and A. J. Coyle, "HMGB1 and RAGE in inflammation and cancer," Annual Review of Immunology, vol. 28, pp. 367-388, 2010.

[55] H. S. Hreggvidsdottir, T. Östberg, H. Wähämaa et al., "The alarmin HMGB1 acts in synergy with endogenous and exogenous danger signals to promote inflammation," Journal of Leukocyte Biology, vol. 86, no. 3, pp. 655-662, 2009.

[56] U. Andersson and K. J. Tracey, "HMGB1 is a therapeutic target for sterile inflammation and infection," Annual Review of Immunology, vol. 29, pp. 139-162, 2011.

[57] H. El-Saghire, A. Michaux, H. Thierens, and S. Baatout, "Low doses of ionizing radiation induce immune-stimulatory responses in isolated human primary monocytes," International Journal of Molecular Medicine, vol. 32, pp. 1407-1414, 2013.

[58] R. K. Wolfson, E. T. Chiang, and J. G. N. Garcia, "HMGB1 induces human lung endothelial cell cytoskeletal rearrangement and barrier disruption," Microvascular Research, vol. 81, no. 2, pp. 189-197, 2011.

[59] E. Abraham, J. Arcaroli, A. Carmody, H. Wang, and K. J. Tracey, "Cutting edge: HMG-1 as a mediator of acute lung inflammation," Journal of Immunology, vol. 165, no. 6, pp. 29502954, 2000.

[60] P. L. Sappington, R. Yang, H. Yang, K. J. Tracey, R. L. Delude, and M. P. Fink, "HMGB1 B box increases the permeability of Caco-2 enterocytic monolayers and impairs intestinal barrier function in mice," Gastroenterology, vol. 123, no. 3, pp. 790-802, 2002.

[61] J.-M. Cavaillon, “Septic plasma”: an immunosuppressive milieu," American Journal of Respiratory and Critical Care Medicine, vol. 166, no. 11, pp. 1417-1418, 2002.

[62] F. Y. F. L. de Vos, P. H. B. Willemse, E. G. E. de Vries, and J. A. Gietema, "Endothelial cell effects of cytotoxics: balance between desired and unwanted effects," Cancer Treatment Reviews, vol. 30, no. 6, pp. 495-513, 2004.

[63] K. Blirando, M. Hneino, I. Martelly, M. Benderitter, F. Milliat, and A. François, "Mast cells and ionizing radiation induce a synergistic expression of inflammatory genes in endothelial cells by a mechanism involving $\mathrm{p} 38 \alpha$ MAP kinase and (p65) NF$\kappa \mathrm{B}$ activation," Radiation Research, vol. 178, pp. 556-567, 2012.

[64] J.-S. Bae, "Role of high mobility group box 1 in inflammatory disease: focus on sepsis," Archives of Pharmacal Research, vol. 35, pp. 1511-1523, 2012.

[65] M. Li, D. F. Carpio, Y. Zheng et al., "An essential role of the NF- $\kappa \mathrm{B} /$ toll-like receptor pathway in induction of inflammatory and tissue-repair gene expression by necrotic cells," Journal of Immunology, vol. 166, no. 12, pp. 7128-7135, 2001.
[66] A. P. Kaplan, K. Joseph, Y. Shibayama, S. Reddigari, B. Ghebrehiwet, and M. Silverberg, "The intrinsic coagulation/kininforming cascade: assembly in plasma and cell surfaces in inflammation," Advances in Immunology, vol. 66, pp. 225-272, 1997.

[67] K. L. Rock and H. Kono, "The inflammatory response to cell death," Annual Review of Pathology, vol. 3, pp. 99-126, 2008.

[68] C. K. Murphy, E. G. Fey, B. A. Watkins, V. Wong, D. Rothstein, and S. T. Sonis, "Efficacy of superoxide dismutase mimetic M40403 in attenuating radiation-induced oral mucositis in hamsters," Clinical Cancer Research, vol. 14, no. 13, pp. 42924297, 2008

[69] P. A. Riley, "Free radicals in biology: oxidative stress and the effects of ionizing radiation," International Journal of Radiation Biology, vol. 65, no. 1, pp. 27-33, 1994.

[70] W. Zhao, D. I. Diz, and M. E. Robbins, "Oxidative damage pathways in relation to normal tissue injury," British Journal of Radiology, vol. 80, no. 1, pp. S23-S31, 2007.

[71] A. Castellheim, O.-L. Brekke, T. Espevik, M. Harboe, and T. E. Mollnes, "Innate immune responses to danger signals in systemic inflammatory response syndrome and sepsis," Scandinavian Journal of Immunology, vol. 69, no. 6, pp. 479-491, 2009.

[72] H. Kono and K. L. Rock, "How dying cells alert the immune system to danger," Nature Reviews Immunology, vol. 8, no. 4, pp. 279-289, 2008.

[73] R. Wadachi and K. M. Hargreaves, "Trigeminal nociceptors express TLR- 4 and CD14: a mechanism for pain due to infection," Journal of Dental Research, vol. 85, no. 1, pp. 49-53, 2006.

[74] T. Liu, Y.-J. Gao, and R.-R. Ji, "Emerging role of Toll-like receptors in the control of pain and itch," Neuroscience Bulletin, vol. 28, pp. 131-144, 2012.

[75] E. Allan, "Skin," in The Radiotherapy of Malignant Disease, pp. 133-144, Springer, New York, NY, USA, 1991.

[76] W. T. Moss and S. Gold, "The acute effects of radiations on the physiology of small blood vessels," The American Journal of Roentgenology, Radium Therapy, and Nuclear Medicine, vol. 90, pp. 294-299, 1963.

[77] L. P. Schramm, "Spinal sympathetic interneurons: their identification and roles after spinal cord injury," in Progress in Brain Research, L. C. Weaver and C. Polosa, Eds., vol. 152, pp. 27-37, Elsevier, 2006.

[78] R. H. Straub, M. Mayer, M. Kreutz, S. Leeb, J. Scholmerich, and W. Falk, "Neurotransmitters of the sympathetic nerve terminal are powerful chemoattractants for monocytes," Journal of Leukocyte Biology, vol. 67, no. 4, pp. 553-558, 2000.

[79] L. F. Fajardo, "The pathology of ionizing radiation as defined by morphologic patterns," Acta Oncologica, vol. 44, no. 1, pp. 13-22, 2005.

[80] P. Goldin-Lang, K. Pels, Q.-V. Tran et al., "Effect of ionizing radiation on cellular procoagulability and co-ordinated gene alterations," Haematologica, vol. 92, no. 8, pp. 1091-1098, 2007.

[81] N. Al-Dasooqi, R. J. Gibson, J. M. Bowen, and D. M. Keefe, "Matrix metalloproteinases: key regulators in the pathogenesis of chemotherapy-induced mucositis?" Cancer Chemotherapy and Pharmacology, vol. 64, no. 1, pp. 1-9, 2009.

[82] W. C. Parks, C. L. Wilson, and Y. S. López-Boado, "Matrix metalloproteinases as modulators of inflammation and innate immunity," Nature Reviews Immunology, vol. 4, no. 8, pp. 617629, 2004.

[83] F. Paris, Z. Fuks, A. Kang et al., "Endothelial apoptosis as the primary lesion initiating intestinal radiation damage in mice," Science, vol. 293, no. 5528, pp. 293-297, 2001. 
[84] C.-Y. Li, Y. Hong, X.-A. Tao, J. Xia, and B. Cheng, "The correlation between the severity of radiotherapy-induced glossitis and endothelial cell injury in local tissues in a rat model," Medicina Oral, Patologia Oral y Cirugia Bucal, vol. 16, no. 6, pp. e711-e715, 2011.

[85] H. J. Wearing and J. A. Sherratt, "Keratinocyte growth factor signalling: a mathematical model of dermal-epidermal interaction in epidermal wound healing," Mathematical Biosciences, vol. 165, no. 1, pp. 41-62, 2000.

[86] R. M. Logan, A. M. Stringer, J. M. Bowen, R. J. Gibson, S. T. Sonis, and D. M. K. Keefe, "Serum levels of NFאB and proinflammatory cytokines following administration of mucotoxic drugs," Cancer Biology and Therapy, vol. 7, no. 7, pp. 1139-1145, 2008.

[87] S. T. Sonis, "Oral complications of cancer therapy," in HollandFrei Cancer Medicine, R. J. Bast, D. Kufe, and R. Pollock, Eds., pp. 2371-2379, BC Decker, Hamilton, Canada, 2000.

[88] H. O. Besedovsky and A. del Rey, "Immune-neuro-endocrine interactions: facts and hypotheses," Endocrine Reviews, vol. 17, no. 1, pp. 64-102, 1996.

[89] P. Ciofi, M. Garret, O. Lapirot et al., "Brain-endocrine interactions: a microvascular route in the mediobasal hypothalamus," Endocrinology, vol. 150, no. 12, pp. 5509-5519, 2009.

[90] C. Schubert, S. Hong, L. Natarajan, P. J. Mills, and J. E. Dimsdale, "The association between fatigue and inflammatory marker levels in cancer patients: a quantitative review," Brain, Behavior, and Immunity, vol. 21, no. 4, pp. 413-427, 2007.

[91] D. C. Guttridge, M. W. Mayo, L. V. Madrid, C.-Y. Wang, and A. S. Baldwin Jr., "NF- $\kappa$ B-induced loss of MyoD messenger RNA: possible role in muscle decay and cachexia," Science, vol. 289, no. 5488, pp. 2363-2365, 2000.

[92] M. Couch, V. Lai, T. Cannon et al., "Cancer cachexia syndrome in head and neck cancer patients: part I. Diagnosis, impact on quality of life and survival, and treatment," Head \& Neck, vol. 29, no. 4, pp. 401-411, 2007.

[93] J. George, T. Cannon, V. Lai et al., "Cancer cachexia syndrome in head and neck cancer patients: part II. Pathophysiology," Head \& Neck, vol. 29, no. 5, pp. 497-507, 2007.

[94] A. J. Grossberg, J. M. Scarlett, and D. L. Marks, "Hypothalamic mechanisms in cachexia," Physiology and Behavior, vol. 100, no. 5, pp. 478-489, 2010.

[95] G. P. Bodey, V. Rodriguez, H. Y. Chang, and G. Narboni, "Fever and infection in leukemic patients. A study of 494 consecutive patients," Cancer, vol. 41, no. 4, pp. 1610-1622, 1978.

[96] S. T. Sonis, "Mucositis: the impact, biology and therapeutic opportunities of oral mucositis," Oral Oncology, vol. 45, no. 12, pp. 1015-1020, 2009.

[97] W. J. Evans, J. E. Morley, J. Argilés et al., "Cachexia: a new definition," Clinical Nutrition, vol. 27, no. 6, pp. 793-799, 2008.

[98] K. Fearon, F. Strasser, S. D. Anker et al., "Definition and classification of cancer cachexia: an international consensus," The Lancet Oncology, vol. 12, no. 5, pp. 489-495, 2011.

[99] T. Pradeu and E. L. Cooper, "The danger theory: 20 years later," Frontiers in Immunology, vol. 3, article 287, 2012.

[100] N. W. Palm and R. Medzhitov, "Pattern recognition receptors and control of adaptive immunity," Immunological Reviews, vol. 227, no. 1, pp. 221-233, 2009.

[101] S. P. Jong, F. Gamboni-Robertson, Q. He et al., "High mobility group box 1 protein interacts with multiple Toll-like receptors," American Journal of Physiology, vol. 290, no. 3, pp. C917-C924, 2006.
[102] A. M. Schmidt, O. Hori, R. Cao et al., "A novel cellular receptor for advanced glycation end products," Diabetes, vol. 45, no. 3, pp. S77-S80, 1996.

[103] T. Criswell, K. Leskov, S. Miyamoto, G. Luo, and D. A. Boothman, "Transcription factors activated in mammalian cells after clinically relevant doses of ionizing radiation," Oncogene, vol. 22, no. 37, pp. 5813-5827, 2003.

[104] J. R. van Beijnum, W. A. Buurman, and A. W. Griffioen, "Convergence and amplification of toll-like receptor (TLR) and receptor for advanced glycation end products (RAGE) signaling pathways via high mobility group B1 (HMGB1)," Angiogenesis, vol. 11, no. 1, pp. 91-99, 2008.

[105] R. M. Logan, R. J. Gibson, S. T. Sonis, and D. M. K. Keefe, "Nuclear factor- $\kappa \mathrm{B}(\mathrm{NF}-\kappa \mathrm{B})$ and cyclooxygenase-2 (COX-2) expression in the oral mucosa following cancer chemotherapy," Oral Oncology, vol. 43, no. 4, pp. 395-401, 2007.

[106] S. T. Sonis, K. E. O’Donnell, R. Popat et al., "The relationship between mucosal cyclooxygenase-2 (COX-2) expression and experimental radiation-induced mucositis," Oral Oncology, vol. 40, no. 2, pp. 170-176, 2004.

[107] F. O. Morvan, B. Baroukh, D. Ledoux et al., "An engineered biopolymer prevents mucositis induced by 5 -fluorouracil in hamsters," American Journal of Pathology, vol. 164, no. 2, pp. 739-746, 2004.

[108] N. Al-Dasooqi, R. J. Gibson, J. M. Bowen, R. M. Logan, A. M. Stringer, and D. M. Keefe, "Matrix metalloproteinases are possible mediators for the development of alimentary tract mucositis in the dark agouti rat," Experimental Biology and Medicine, vol. 235, no. 10, pp. 1244-1256, 2010.

[109] A. I. Basbaum, D. M. Bautista, G. Scherrer, and D. Julius, "Cellular and molecular mechanisms of pain," Cell, vol. 139, no. 2, pp. 267-284, 2009.

[110] M. L. Castellani, C. Ciampoli, M. Felaco et al., "Neuropeptide substance $\mathrm{P}$ induces mRNA expression and secretion of CXCL8 chemokine, and HDC in human umbilical cord blood mast cells," Clinical and Investigative Medicine, vol. 31, no. 6, pp. E362-E372, 2008.

[111] A. B. Guadagnolo, K. K. Ang, and M. T. Ballo, “The skin,” in Radiation Oncology: Rationale, Technique, Results, pp. 141-157, Mosby, 2009.

[112] R. M. Logan, A. M. Stringer, J. M. Bowen et al., "The role of pro-inflammatory cytokines in cancer treatment-induced alimentary tract mucositis: pathobiology, animal models and cytotoxic drugs," Cancer Treatment Reviews, vol. 33, no. 5, pp. 448-460, 2007.

[113] R. M. Logan, R. J. Gibson, J. M. Bowen, A. M. Stringer, S. T. Sonis, and D. M. K. Keefe, "Characterisation of mucosal changes in the alimentary tract following administration of irinotecan: implications for the pathobiology of mucositis," Cancer Chemotherapy and Pharmacology, vol. 62, no. 1, pp. 3341, 2008.

[114] N. Andrieu-Abadie and T. Levade, "Sphingomyelin hydrolysis during apoptosis," Biochimica et Biophysica Acta, vol. 1585, no. 2-3, pp. 126-134, 2002.

[115] M.-T. Dimanche-Boitrel and A. Rebillard, "Sphingolipids and response to chemotherapy," Sphingolipids in Disease, Springer, vol. 216, pp. 73-91, 2013.

[116] R. Kolesnick and Z. Fuks, "Radiation and ceramide-induced apoptosis," Oncogene, vol. 22, no. 37, pp. 5897-5906, 2003.

[117] R. J. Davis, "Signal transduction by the JNK group of MAP kinases," in Inflammatory Processes, D. L. G. Letts and D. D. W. Morgan, Eds., pp. 13-21, Birkhäuser, Basel, Switzerland, 2000. 
[118] S. T. Sonis, L. S. Elting, D. Keefe et al., "Perspectives on cancer therapy-induced mucosal injury: pathogenesis, measurement, epidemiology, and consequences for patients," Cancer, vol. 100, no. 9, pp. 1995-2025, 2004.

[119] B. A. E. de Koning, J. M. van Dieren, D. J. Lindenbergh-Kortleve et al., "Contributions of mucosal immune cells to methotrexateinduced mucositis," International Immunology, vol. 18, no. 6, pp. 941-949, 2006.

[120] R. J. Gibson, D. M. K. Keefe, F. M. Thompson, J. M. Clarke, G. J. Goland, and A. G. Cummins, "Effect of interleukin-11 on ameliorating intestinal damage after methotrexate treatment of breast cancer in rats," Digestive Diseases and Sciences, vol. 47, no. 12, pp. 2751-2757, 2002.

[121] S. T. Sonis, R. L. Peterson, L. J. Edwards et al., "Defining mechanisms of action of interleukin-11 on the progression of radiation-induced oral mucositis in hamsters," Oral Oncology, vol. 36, no. 4, pp. 373-381, 2000.

[122] J. Zhao, L. Huang, N. Belmar, R. Buelow, and T. Fong, "Oral RDP58 allows CPT-11 dose intensification for enhanced tumor response by decreasing gastrointestinal toxicity," Clinical Cancer Research, vol. 10, no. 8, pp. 2851-2859, 2004.

[123] J. H. Antin, S. J. Lee, D. Neuberg et al., "A phase I/II double-blind, placebo-controlled study of recombinant human interleukin-11 for mucositis and acute GVHD prevention in allogeneic stem cell transplantation," Bone Marrow Transplantation, vol. 29, no. 5, pp. 373-377, 2002.

[124] R. M. Logan, A. M. Stringer, J. M. Bowen, R. J. Gibson, S. T. Sonis, and D. M. K. Keefe, "Is the pathobiology of chemotherapy-induced alimentary tract mucositis influenced by the type of mucotoxic drug administered?" Cancer Chemotherapy and Pharmacology, vol. 63, no. 2, pp. 239-251, 2009.

[125] Z. Y. Ong, R. J. Gibson, J. M. Bowen et al., "Pro-inflammatory cytokines play a key role in the development of radiotherapyinduced gastrointestinal mucositis," Radiation Oncology, vol. 5, no. 1 , article 22, 2010.

[126] S. T. Sonis, J. Scherer, S. Phelan et al., "The gene expression sequence of radiated mucosa in in an animal mucositis model," Cell Proliferation, vol. 35, supplement 1, pp. 93-102, 2002.

[127] C. Ferrà, S. de Sanjosé, C. F. Lastra et al., "Pentoxifylline, ciprofloxacin and prednisone failed to prevent transplantrelated toxicities in bone marrow transplant recipients and were associated with an increased incidence of infectious complications," Bone Marrow Transplantation, vol. 20, no. 12, pp. 1075-1080, 1997.

[128] Q.-T. Le, H. E. Kim, C. J. Schneider et al., "Palifermin reduces severe mucositis in definitive chemoradiotherapy of locally advanced head and neck cancer: a randomized, placebocontrolled study," Journal of Clinical Oncology, vol. 29, no. 20, pp. 2808-2814, 2011.

[129] S. T. Sonis, "Efficacy of palifermin (keratinocyte growth factor1) in the amelioration of oral mucositis," Core Evidence, vol. 4, pp. 199-205, 2009.

[130] A. W. Beaven and T. C. Shea, "Recombinant human keratinocyte growth factor palifermin reduces oral mucositis and improves patient outcomes after stem cell transplant," Drugs of Today, vol. 43, no. 7, pp. 461-473, 2007.

[131] A. H. E. Herbers, W. J. F. M. van der Velden, A. F. J. de Haan, J. P. Donnelly, and N. M. A. Blijlevens, "Impact of palifermin on intestinal mucositis of HSCT recipients after BEAM," Bone Marrow Transplant, vol. 49, pp. 8-10, 2014.
[132] S. T. Sonis, L. S. Schwartzberg, S. M. Weidner, and G. Alterovitz, "From Bayesian modeling to genomic mapping: biologic validity of predictive single nucleotide polymorphism networks for chemotherapy-related side effects," Journal of Clinical Oncology, vol. 31, abstract 9535, 2013.

[133] A. van der Meeren, M. Vandamme, C. Squiban, M.-H. Gaugler, and M.-A. Mouthon, "Inflammatory reaction and changes in expression of coagulation proteins on lung endothelial cells after total-body irradiation in mice," Radiation Research, vol. 160, no. 6, pp. 637-646, 2003.

[134] J. Panés, D. C. Anderson, M. Miyasaka, and D. N. Granger, "Role of leukocyte-endothelial cell adhesion in radiation-induced microvascular dysfunction in rats," Gastroenterology, vol. 108, no. 6, pp. 1761-1769, 1995.

[135] J. Wu, M. J. Stevenson, J. M. Brown, E. A. Grunz, T. L. Strawn, and W. P. Fay, "C-reactive protein enhances tissue factor expression by vascular smooth muscle cells: mechanisms and in vivo significance," Arteriosclerosis, Thrombosis, and Vascular Biology, vol. 28, no. 4, pp. 698-704, 2008.

[136] E. Napoleone, A. di Santo, G. Peri et al., “The long pentraxin PTX3 up-regulates tissue factor in activated monocytes: another link between inflammation and clotting activation," Journal of Leukocyte Biology, vol. 76, no. 1, pp. 203-209, 2004.

[137] A. J. Chu, "Tissue factor, blood coagulation, and beyond: an overview," International Journal of Inflammation, vol. 2011, Article ID 367284, 30 pages, 2011.

[138] E. M. Conway, "Thrombomodulin and its role in inflammation," Seminars in Immunopathology, vol. 34, no. 1, pp. 107-125, 2012.

[139] M. Delvaeye and E. M. Conway, "Coagulation and innate immune responses: can we view them separately?" Blood, vol. 114, no. 12, pp. 2367-2374, 2009.

[140] J. Wang, H. Zheng, X. Ou et al., "Hirudin ameliorates intestinal radiation toxicity in the rat: support for thrombin inhibition as strategy to minimize side-effects after radiation therapy and as countermeasure against radiation exposure," Journal of Thrombosis and Haemostasis, vol. 2, no. 11, pp. 2027-2035, 2004.

[141] N. Al-Dasooqi, J. M. Bowen, R. J. Gibson, R. M. Logan, A. M. Stringer, and D. M. Keefe, "Irinotecan-induced alterations in intestinal cell kinetics and extracellular matrix component expression in the dark agouti rat," International Journal of Experimental Pathology, vol. 92, no. 5, pp. 357-365, 2011.

[142] M. H. Barcellos-Hoff, "How do tissues respond to damage at the cellular level? The role of cytokines in irradiated tissues," Radiation Research, vol. 150, no. 5, pp. S109-S120, 1998.

[143] J. Yarnold and M.-C. V. Brotons, "Pathogenetic mechanisms in radiation fibrosis," Radiotherapy and Oncology, vol. 97, no. 1, pp. 149-161, 2010.

[144] H. E. van Wart and H. Birkedal-Hansen, "The cysteine switch: a principle of regulation of metalloproteinase activity with potential applicability to the entire matrix metalloproteinase gene family," Proceedings of the National Academy of Sciences of the United States of America, vol. 87, no. 14, pp. 5578-5582, 1990.

[145] R. H. Mole, "Whole body irradiation; radiobiology or medicine?” The British Journal of Radiology, vol. 26, no. 305, pp. 234241, 1953.

[146] C. A. Dinarello, "Historical insights into cytokines," European Journal of Immunology, vol. 37, no. 1, pp. S34-S45, 2007.

[147] J.-M. Cavaillon, C. Munoz, C. Fitting, B. Misset, and J. Carlet, "Circulating cytokines: the tip of the iceberg?" Circulatory Shock, vol. 38, no. 2, pp. 145-152, 1992. 
[148] J. E. Bower, P. A. Ganz, L. T. May et al., "Inflammatory biomarkers and fatigue during radiation therapy for breast and prostate cancer," Clinical Cancer Research, vol. 15, no. 17, pp. 5534-5540, 2009.

[149] J. E. Bower, P. A. Ganz, M. R. Irwin, J. M. G. Arevalo, and S. W. Cole, "Fatigue and gene expression in human leukocytes: increased NF- $\kappa$ B and decreased glucocorticoid signaling in breast cancer survivors with persistent fatigue," Brain, Behavior, and Immunity, vol. 25, no. 1, pp. 147-150, 2011.

[150] C.-K. Min, W. Y. Lee, D.-J. Min et al., "The kinetics of circulating cytokines including IL-6, TNF- $\alpha$, IL-8 and IL-10 following allogeneic hematopoietic stem cell transplantation," Bone Marrow Transplantation, vol. 28, no. 10, pp. 935-940, 2001.

[151] C. Wratten, J. Kilmurray, S. Nash et al., "Fatigue during breast radiotherapy and its relationship to biological factors," International Journal of Radiation Oncology, Biology, Physics, vol. 59, no. 1, pp. 160-167, 2004.

[152] H. Landmark-Høyvik, K. V. Reinertsen, J. H. Loge, S. D. Fosså, A. L. Børresen-Dale, and V. Dumeaux, "Alterations of gene expression in blood cells associated with chronic fatigue in breast cancer survivors," Pharmacogenomics Journal, vol. 9, no. 5, pp. 333-340, 2009.

[153] A. Rishi and S. Ghoshal, "Acute multiple arterial thrombosis after cisplatin in base of tongue carcinoma: case report," Head \& Neck, vol. 35, pp. E269-E271, 2013.

[154] R. Haddad, S. Sonis, M. Posner et al., "Randomized phase 2 study of concomitant chemoradiotherapy using weekly carboplatin/paclitaxel with or without daily subcutaneous amifostine in patients with locally advanced head and neck cancer," Cancer, vol. 115, no. 19, pp. 4514-4523, 2009.

[155] N. M. A. Blijlevens, J. P. Donnelly, and B. E. DePauw, "Inflammatory response to mucosal barrier injury after myeloablative therapy in allogeneic stem cell transplant recipients," Bone Marrow Transplantation, vol. 36, no. 8, pp. 703-707, 2005.

[156] N. M. A. Blijlevens, R. M. Logan, and M. G. Netea, "The changing face of febrile neutropenia-from monotherapy to moulds to mucositis. Mucositis: from febrile neutropenia to febrile mucositis," The Journal of Antimicrobial Chemotherapy, vol. 63, pp. i36-i40, 2009.

[157] J. P. Donnelly, P. Muus, A. M. Horrevorts, R. W. Sauerwein, and B. E. DePauw, "Failure of clindamycin to influence the course of severe oromucositis associated with streptococcal bacteraemia in allogeneic bone marrow transplant recipients," Scandinavian Journal of Infectious Diseases, vol. 25, no. 1, pp. 43-50, 1993.

[158] H. Takatsuka, Y. Takemoto, S. Yamada et al., "Complications after bone marrow transplatation are manifestations of systemic inflammatory response syndrome," Bone Marrow Transplantation, vol. 26, no. 4, pp. 419-426, 2000.

[159] M. E. Haisfield-Wolfe, D. B. McGuire, K. Soeken, J. GeigerBrown, B. de Forge, and M. Suntharalingam, "Prevalence and correlates of symptoms and uncertainty in illness among head and neck cancer patients receiving definitive radiation with or without chemotherapy," Supportive Care in Cancer, vol. 20, pp. 1885-1893, 2011.

[160] Y. Ye, G. Carlsson, M. B. Agholme et al., "Pretherapeutic plasma pro- and anti-inflammatory mediators are related to high risk of oral mucositis in pediatric patients with acute leukemia: a prospective cohort study," PLOS ONE, vol. 8, no. 5, Article ID e64918, 2013.

[161] G. Pongratz and R. H. Straub, "Role of peripheral nerve fibres in acute and chronic inflammation in arthritis," Nature Reviews Rheumatology, vol. 9, pp. 117-126, 2013.
[162] R. H. Straub, M. Cutolo, F. Buttgereit, and G. Pongratz, "Energy regulation and neuroendocrine-immune control in chronic inflammatory diseases," Journal of Internal Medicine, vol. 267, no. 6, pp. 543-560, 2010.

[163] V. A. Pavlov and K. J. Tracey, "Controlling inflammation: the cholinergic anti-inflammatory pathway," Biochemical Society Transactions, vol. 34, no. 6, pp. 1037-1040, 2006.

[164] L. Ulloa, "The vagus nerve and the nicotinic anti-inflammatory pathway," Nature Reviews Drug Discovery, vol. 4, no. 8, pp. 673684, 2005.

[165] R. S. Goldstein, A. Bruchfeld, L. Yang et al., "Cholinergic antiinflammatory pathway activity and High Mobility Group Box-1 (HMGB1) serum levels in patients with rheumatoid arthritis," Molecular Medicine, vol. 13, no. 3-4, pp. 210-215, 2007.

[166] H. Wang, M. Yu, M. Ochani et al., "Nicotinic acetylcholine receptor $\alpha 7$ subunit is an essential regulator of inflammation," Nature, vol. 421, no. 6921, pp. 384-388, 2003.

[167] L. V. Borovikova, S. Ivanova, M. Zhang et al., "Vagus nerve stimulation attenuates the systemic inflammatory response to endotoxin," Nature, vol. 405, no. 6785, pp. 458-462, 2000.

[168] R. W. Saeed, S. Varma, T. Peng-Nemeroff et al., "Cholinergic stimulation blocks endothelial cell activation and leukocyte recruitment during inflammation," Journal of Experimental Medicine, vol. 201, no. 7, pp. 1113-1123, 2005.

[169] D. J. F. Brown, D. C. McMillan, and R. Milroy, “The correlation between fatigue, physical function, the systemic inflammatory response, and psychological distress in patients with advanced lung cancer," Cancer, vol. 103, no. 2, pp. 377-382, 2005.

[170] R. C. Bone, "Toward a theory regarding the pathogenesis of the systemic inflammatory response syndrome: what we do and do not know about cytokine regulation," Critical Care Medicine, vol. 24, no. 1, pp. 163-172, 1996.

[171] W. J. Evans and C. P. Lambert, "Physiological basis of fatigue," American Journal of Physical Medicine and Rehabilitation, vol. 86, no. 1, pp. S29-S46, 2007.

[172] P. C. Stone and O. Minton, "Cancer-related fatigue," European Journal of Cancer, vol. 44, no. 8, pp. 1097-1104, 2008.

[173] G. Prue, J. Rankin, J. Allen, J. Gracey, and F. Cramp, “Cancerrelated fatigue: a critical appraisal," European Journal of Cancer, vol. 42, no. 7, pp. 846-863, 2006.

[174] B. A. Jereczek-Fossa, H. R. Marsiglia, and R. Orecchia, "Radiotherapy-related fatigue," Critical Reviews in Oncology/Hematology, vol. 41, no. 3, pp. 317-325, 2002.

[175] N. O. Sawada, J. M. de Paula, H. M. Sonobe, M. M. F. Zago, G. P. Guerrero, and A. C. Nicolussi, "Depression, fatigue, and health-related quality of life in head and neck cancer patients: a prospective pilot study," Supportive Care in Cancer, vol. 20, pp. 2705-2711, 2012.

[176] E. M. A. Smets, M. R. M. Visser, A. F. M. N. Willems-Groot, B. Garssen, A. L. J. Schuster-Uitterhoeve, and J. C. J. M. de Haes, "Fatigue and radiotherapy: (B) experience in patients 9 months following treatment," British Journal of Cancer, vol. 78, no. 7, pp. 907-912, 1998.

[177] M. R. M. Visser and E. M. A. Smets, "Fatigue, depression and quality of life in cancer patients: how are they related?" Supportive Care in Cancer, vol. 6, no. 2, pp. 101-108, 1998.

[178] G. R. Morrow, J. T. Hickok, J. A. Roscoe et al., "Differential effects of paroxetine on fatigue and depression: a randomized, double-blind trial from the University of Rochester Cancer Center Community Clinical Oncology Program," Journal of Clinical Oncology, vol. 21, no. 24, pp. 4635-4641, 2003. 
[179] J. A. Roscoe, G. R. Morrow, J. T. Hickok et al., "Effect of paroxetine hydrochloride (Paxil) on fatigue and depression in breast cancer patients receiving chemotherapy," Breast Cancer Research and Treatment, vol. 89, no. 3, pp. 243-249, 2005.

[180] A. Collado-Hidalgo, J. E. Bower, P. A. Ganz, S. W. Cole, and M. R. Irwin, "Inflammatory biomarkers for persistent fatigue in breast cancer survivors," Clinical Cancer Research, vol. 12, no. 9, pp. 2759-2766, 2006.

[181] L. N. Saligan and H. S. Kim, "A systematic review of the association between immunogenomic markers and cancerrelated fatigue," Brain, Behavior, and Immunity, vol. 26, pp. 830848, 2012.

[182] K. M. Fox, J. M. Brooks, S. R. Gandra, R. Markus, and C.-F. Chiou, "Estimation of cachexia among cancer patients based on four definitions," Journal of Oncology, vol. 2009, Article ID 693458, 7 pages, 2009.

[183] R. J. E. Skipworth, G. D. Stewart, C. H. C. Dejong, T. Preston, and K. C. H. Fearon, "Pathophysiology of cancer cachexia: much more than host-tumour interaction?" Clinical Nutrition, vol. 26, no. 6, pp. 667-676, 2007.

[184] L. M. Richey, J. R. George, M. E. Couch et al., "Defining cancer cachexia in head and neck squamous cell carcinoma," Clinical Cancer Research, vol. 13, no. 22, pp. 6561-6567, 2007.

[185] H. J. Silver, M. S. Dietrich, and B. A. Murphy, "Changes in body mass, energy balance, physical function, and inflammatory state in patients with locally advanced head and neck cancer treated with concurrent chemoradiation after low-dose induction chemotherapy," Head \& Neck, vol. 29, no. 10, pp. 893900, 2007.

[186] A. Jatoi, H. L. Ritter, A. Dueck et al., "A placebo-controlled, double-blind trial of infliximab for cancer-associated weight loss in elderly and/or poor performance non-small cell lung cancer patients (N01C9)," Lung Cancer, vol. 68, no. 2, pp. 234239, 2010

[187] M. Maltoni, L. Fabbri, O. Nanni et al., "Serum levels of tumour necrosis factor alpha and other cytokines do not correlate with weight loss and anorexia in cancer patients," Supportive Care in Cancer, vol. 5, no. 2, pp. 130-135, 1997.

[188] R. C. J. Langen, A. M. W. J. Schols, M. C. J. M. Kelders, E. F. M. Wouters, and Y. M. W. Janssen-Heininger, "Inflammatory cytokines inhibit myogenic differentiation through activation of nuclear factor- $\kappa$ B," FASEB Journal, vol. 15, no. 7, pp. 1169-1180, 2001.

[189] V. Baracos, H. P. Rodemann, C. A. Dinarello, and A. L. Goldberg, "Stimulation of muscle protein degradation and prostaglandin E2 release by leukocyte pyrogen (interleukin-1). A mechanism for the increased degradation of muscle proteins during fever," The New England Journal of Medicine, vol. 308, no. 10, pp. 553-558, 1983.

[190] C. R. Plata-Salamán, G. Sonti, J. P. Borkoski, C. D. Wilson, and J. M. H. Ffrench-Mullen, "Anorexia induced by chronic central administration of cytokines at estimated pathophysiological concentrations," Physiology and Behavior, vol. 60, no. 3, pp. 867875,1996

[191] V. Chesnokova, A. Kariagina, and S. Melmed, "Opposing effects of pituitary leukemia inhibitory factor and SOCS-3 on the ACTH axis response to inflammation," American Journal of Physiology, vol. 282, no. 5, pp. E1110-E1118, 2002.

[192] K. Bendtzen, L. Baek, and D. Berild, "Demonstration of circulating leukocytic pyrogen/interleukin-1 during fever," The New England Journal of Medicine, vol. 310, no. 9, article 596, 1984.
[193] J. V. Castell, M. J. Gomez-Lechon, M. David et al., "Interleukin6 is the major regulator of acute phase protein synthesis in adult human hepatocytes," FEBS Letters, vol. 242, no. 2, pp. 237-239, 1989.

[194] T. J. Bayliss, J. T. Smith, M. Schuster, K. H. Dragnev, and J. R. Rigas, "A humanized anti-IL-6 antibody (ALD518) in non-small cell lung cancer," Expert Opinion on Biological Therapy, vol. 11, no. 12, pp. 1663-1668, 2011.

[195] C. Kubrak, K. Olson, N. Jha et al., "Clinical determinants of weight loss in patients receiving radiation and chemoirradiation for head and neck cancer: a prospective longitudinal view," Head \& Neck, vol. 35, no. 5, pp. 695-703, 2013.

[196] E. G. Russi, R. Corvò, A. Merlotti et al., "Swallowing dysfunction in head and neck cancer patients treated by radiotherapy: review and recommendations of the supportive task group of the Italian Association of Radiation Oncology," Cancer Treatment Reviews, vol. 38, pp. 1033-1049, 2012. 


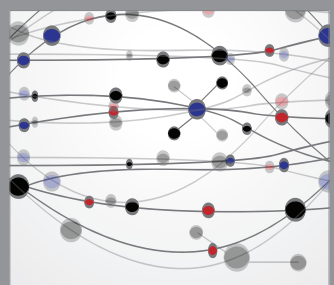

The Scientific World Journal
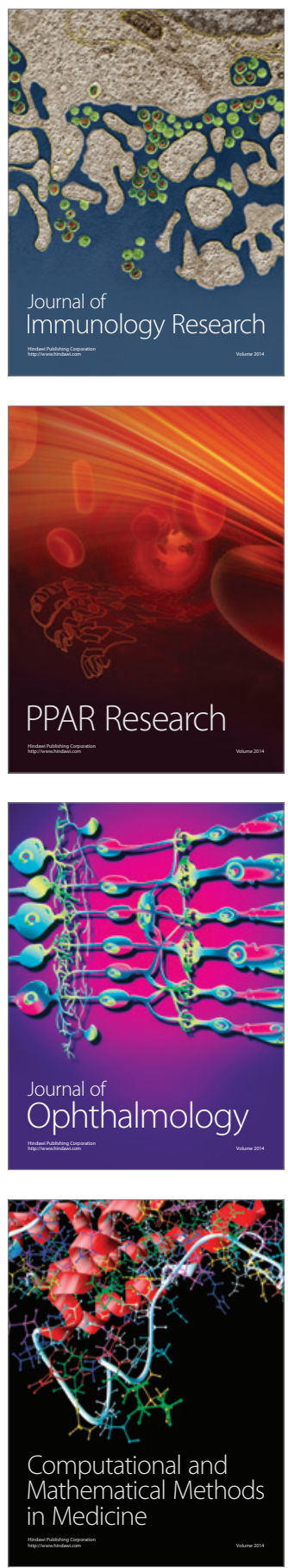

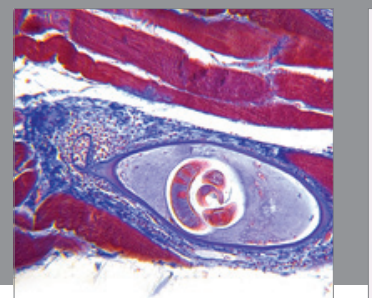

Gastroenterology

Research and Practice
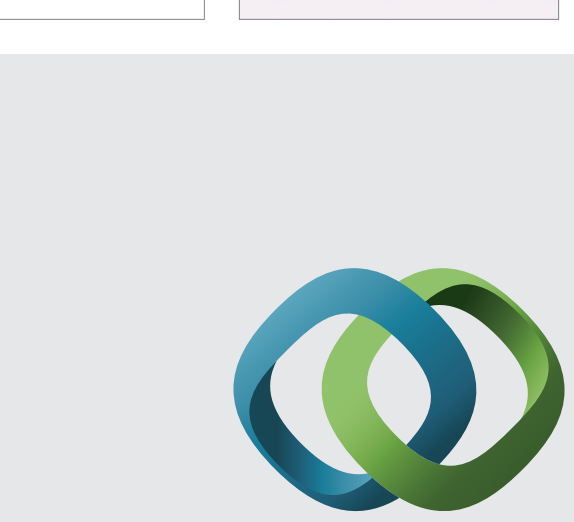

\section{Hindawi}

Submit your manuscripts at

http://www.hindawi.com
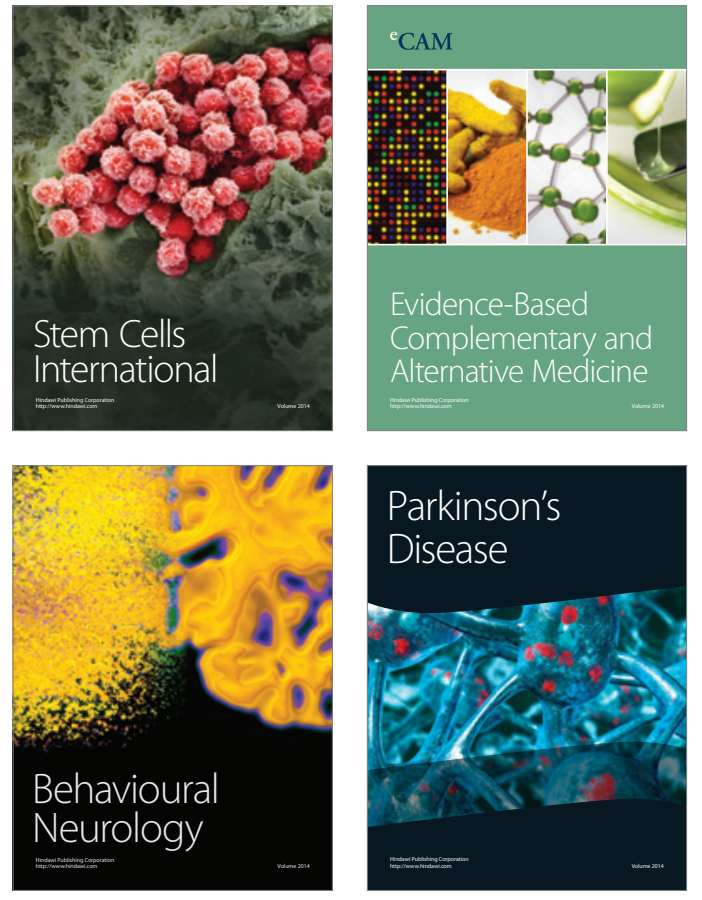
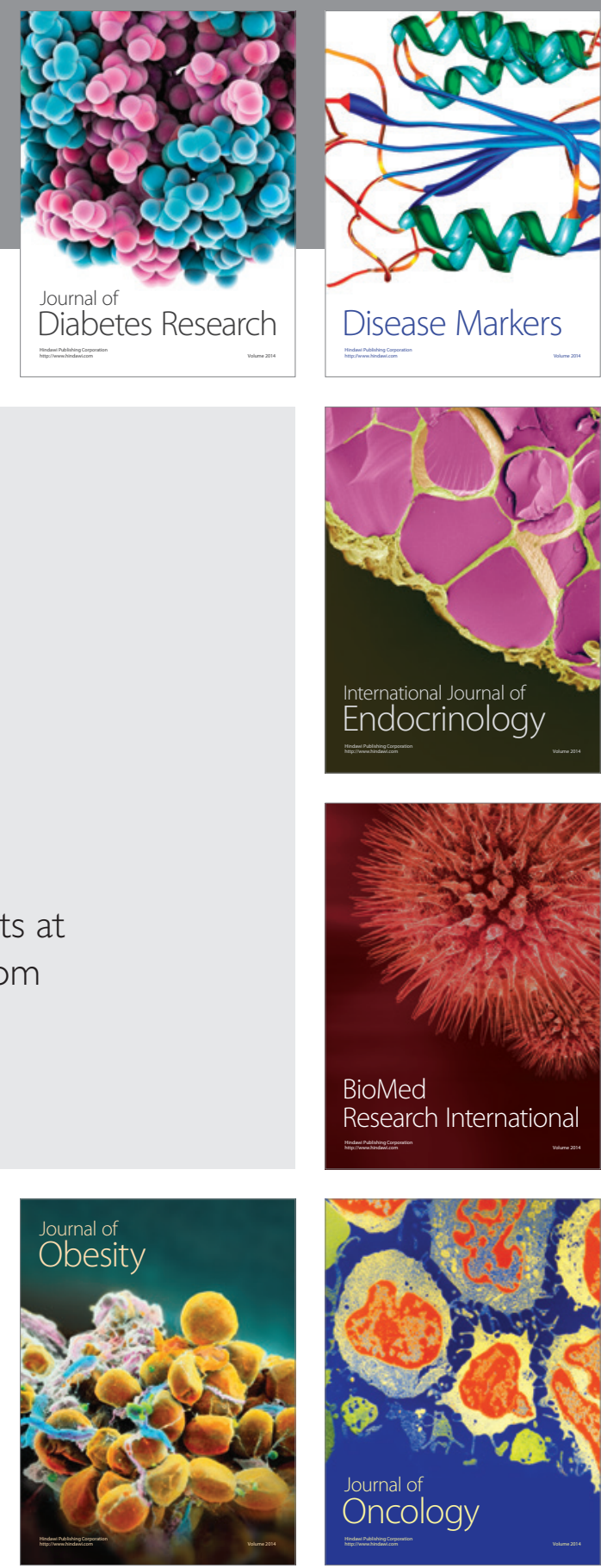

Disease Markers
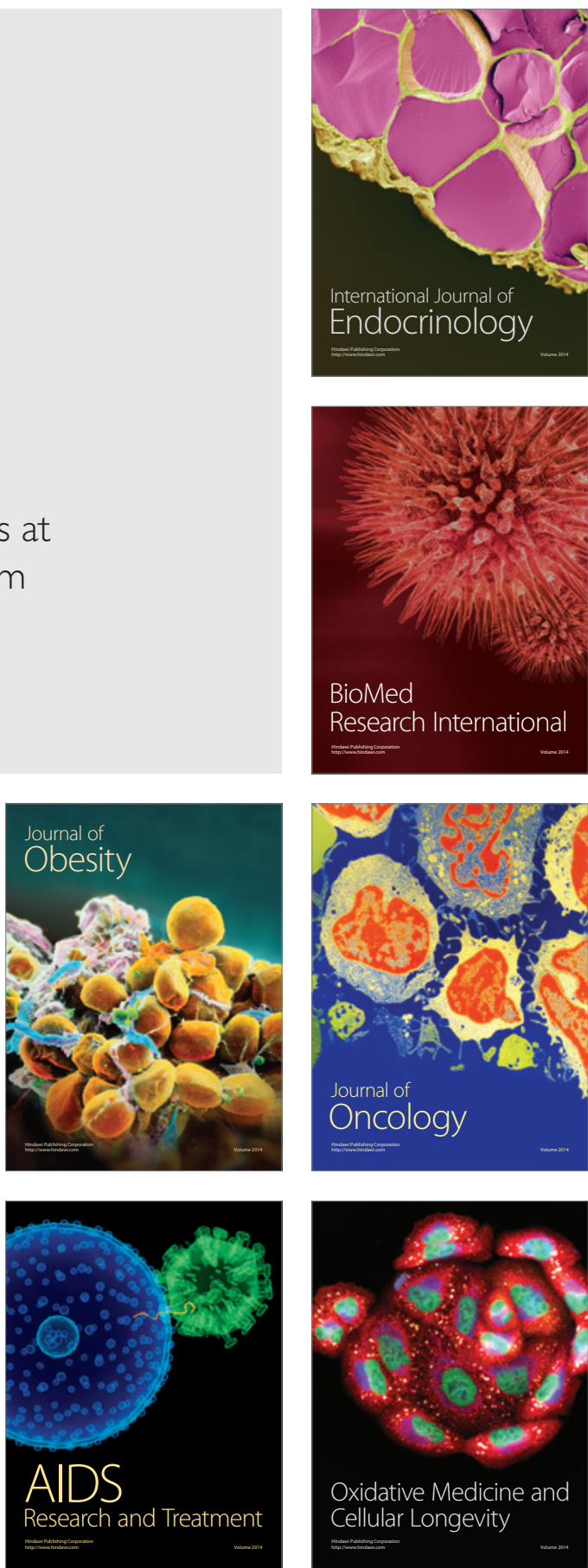